\title{
Using Histoplasmin and Coccidioidin Skin Tests and an Agar Gel Immunodiffusion for Animals in Argentina
}

\author{
Dra Nora Guida \\ Cathedra of Infectious Diseases, Faculty of Veterinary Sciences, University of Buenos Aires, Argentina \\ Email:nguida@fvet.uba.ar, guidanora@gmail.com
}

Received 2 June 2016; accepted 24 June 2016; published 28 June 2016

Copyright (C) 2016 by author and OALib.

This work is licensed under the Creative Commons Attribution International License (CC BY). http://creativecommons.org/licenses/by/4.0/

(c) (i) Open Access

\begin{abstract}
The overall objective of this study was to apply different diagnostic methods that demonstrate the presence of infection or diseases, specifically Histoplasmosis and Coccidioidomycosis, in domestic animals as a contribution to the understanding of mycology in animal health, clinical practice and epidemiology. Sera were studied and skin tests were performed in pigs, horses, dogs and cattle in endemic areas of Argentina as a means of diagnosis and to determine if the fungi of interest were present in the region. Responses to intradermal reactions develop slowly (24 - 72 hours) after administration of an allergen, causing erythema and a nodule and serum with Histoplasmosis or Coccidioidomycosis shows precipitation $M$ and $H$ bands in an agar gel immunodiffusion (AGID), which indicates infection or lesion activity and is not influenced by previous intradermal reaction. Two (2) animals were positive for the skin test, and three (3) were positive for the $M$ band in the AGDI for Coccidioidomycosis. In the case of Histoplasmosis, twenty-eight (28) animals were positive for the M band in the AGID and three (3) were positive for the skin test. The skin test with specific antigens for Coccidioidomycosis and Histoplasmosis is feasible for use in individual diagnostic studies in cattle, equines, canines, and in epidemiological surveys of cattle and pigs, according to the requirements of the this technique for the different species. The use of AGID as a serological technique for Histoplasmosis and Coccidioidomycosis proved to be simple, inexpensive, and effective; it was feasible for use for individual diagnosis in animals with present or past infection and for serological epidemiology due to the ease of application. This method can to be utilized in future studies to determine the prevalence and boundaries of endemic areas.
\end{abstract}

\section{Keywords}

Mycosis, Animals, Serology, Skin Test, Histoplasmin, Coccidioidin

Subject Areas: Infectious Diseases 


\section{Background}

Fungi play a very important role in the slow and constant changes occurring around us. Fungi are capable of producing disease and can live as parasites in the host, thereby causing endogenous infection, or live in the environment, causing exogenous infection (for example, primary pulmonary infection with systemic mycoses).

Most of the pathogenic fungi causing exogenous infection can inhabit soil as saprophytes in areas with certain geographical and climatic qualities, originating in the presence of different organic substances found in endemic regions; in these regions, these substances are common sources of infection for humans and animals [1].

Species that occupy us are saprophytic in nature. Mycelium morphology is similar to that of other parasitic animals, showing similarities in saprophytic structures, with some variation occurring in the unicellular yeast forms or in the spores (fungal dimorphism) [2]. Most infections are asymptomatic or have mild respiratory symptoms that heal spontaneously.

The severe clinical forms of primary infection are produced by a massive inhalation of spores or as a failure in the local or general mechanisms of immunity.

Surveys conducted in humans for Coccidioidomycosis reveal that fungal infection is very common in endemic areas with hot summers (over $26^{\circ} \mathrm{C}$ ), mild winters $\left(4^{\circ} \mathrm{C}\right.$ to $12^{\circ} \mathrm{C}$ ), sparse vegetation, annual rainfall of 20 to $400 \mathrm{~mm}$, alkaline soil and windy conditions leading to the maintenance and spread of the fungus [3].

Histoplasmosis has a worldwide distribution and is endemic in areas with a special microclimate in the soil enriched by bird droppings or bats guano, high humidity and temperature, a pH 5 - 10, and a growth depth of 1 $3 \mathrm{~cm}$.

In our country, this is the first time that a study on fungal infections in domesticated species has been conducted in several geographic areas.

The objective of this study was to determine the feasibility of using skin tests and agar gel immunodiffusion (AGID) on the cattle, horses, pigs, and dogs that inhabit areas with an ecogeography and habitat compatible with Coccidioides posadasii (C. posadassi) [4] and Histoplasma capsulatum (H. capsulatum) [5] [6].

The endemic area for Coccidioidomycosis is located exclusively in the Americas. In Argentina, the fungus inhabits the foothills arid zone, from the province of Jujuy to the province of Río Negro [5].

In Argentina the Histoplasmosis has been reported in the region known as Pampas including Buenos Aires, Entre Ríos, South and Central Santa Fe, Córdoba South-East and East of La Pampa, Corrientes y humid Chaco [7] [8] (Figure 1).

Mycological immunology covers the study of those physiological processes by which the host maintains consistency and integrity of its internal environment and the mechanisms that give the animal the ability to recognize and neutralize or metabolize strange elements, such as spores and filaments, with or without prejudice to its own tissues. Cellular immunity is the actual mechanism by which the body defends itself against invasion by fungal antigens.

Patients with systemic fungal disease are not deficient in antibody production, and serologic tests are of diagnostic and prognostic value.

The agar gel immunodiffusion (AGID) assay is an IgG and IgM-specific test but may not be sensitive enough, whereas an ELISA is also an IgG- and IgM-sensitive test but commonly yields false positives. Serological tests appear to be poor diagnostic methods for use in animals.

Serum from human patients with Histoplasmosis or Coccidioidomycosis has precipitation bands in the AGID, which indicate lesion activity and are not influenced by previous intradermal reactions. The antibodies responsible for both diseases are IgG immune.

These systemic mycoses are characterized by their tendency to be chronic. Macrophages cannot engulf the fungal elements of these fungi in their whole or digest them. The characteristic, chronic inflammatory reaction called "granuloma," in which fungi survive until accompanied by cellular immune response, occurs as delayed hypersensitivity.

In this type of reaction, the mechanism of injury is due to the action of the T lymphocyte-sensitized, cytophilic carrier antibodies that are IgM-specific on the surface, where when bound to specific immunogens, they are stimulated to become killer lymphocytes and secrete effector molecules designated as lymphokines; these lymphokines are responsible for delayed hypersensitivity, and the injuries from these are similar to those caused by Tuberculosis [9] [10].

The intradermal reaction develops slowly (24 - 72 hours) in response to the administration of the allergen, causing erythema and a nodule. In the most severe reactions, bleeding and necrosis occur [9]. 


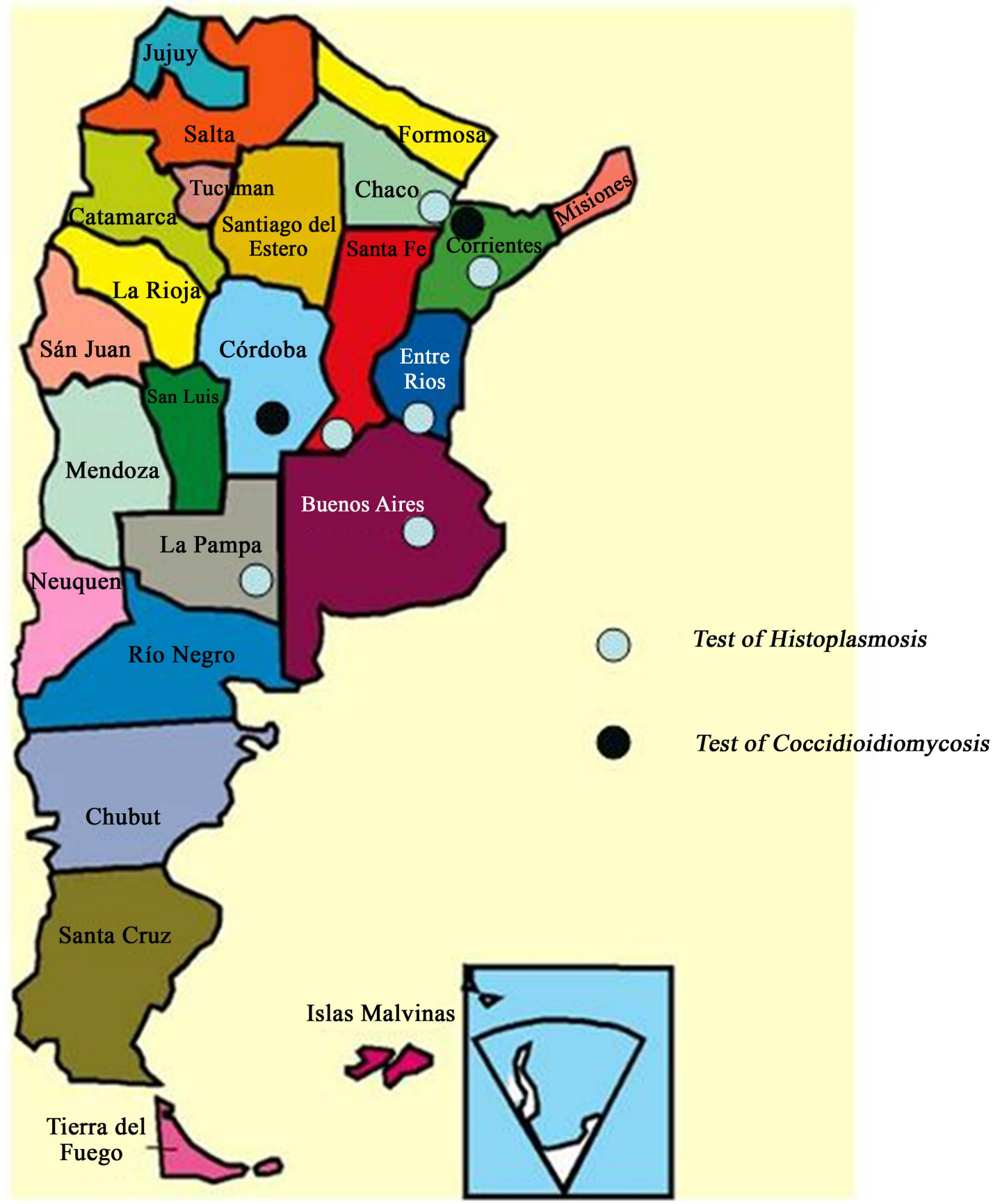

Figure 1. Map of the Argentine Republic with its provinces. http://www.todo-argentina.net/Geografia/Parques/argentina.gif.

The results of the skin tests support the concept that animals can be reservoirs [11].

Based on a description of the Argentine territory, ecogeographic maps were developed highlighting the potential habitat of $\mathrm{H}$ capsulatum (soils rich in nitrogen, acid $\mathrm{pH}$, and mean annual temperature of $15^{\circ} \mathrm{C}-16^{\circ} \mathrm{C}$ and relative humidity of $67 \%$ - 87\%) [11] and C posadasii (dry soils, alkaline, with no major rainfall and 500 - 600 mm rainfall annually).

The literature on specific animal studies is scarce and sporadic, indicating a discontinuity in the investigation of these diseases and little interest within the veterinary profession.

The inclusion of a conceptual framework for a paradigm of medical infectious diseases will be the task of the 
veterinary surgeon, epidemiologist and microbiologist, and the development of a cumulative paradigm is favored to contribute to the dissemination of knowledge in the context of normal science.

\section{Material and Methods}

To meet the objective of the study, which was to determine if specific domesticated animals present with infections from endemic saprozoonoses that are caused in humans and animals by spores from the soil, we proposed to work with not less than 10 animals per species from habitat appropriate for the fungi studied. Córdoba and Corrientes Provincies for Coccidioidiomicosis and Buenos Aires, Santa Fe, Córdoba La Pampa, Chaco, Corrientes y Entre Ríos Province of Histoplasmosis.

The $H$. capsulatum antigen for IDGA was produced from a culture of dog strain autochthon (UBA/297/89) isolated from the province the Entre Rios, in Asparagines medium ( L-Asparagines 1g, Dipotassium phosphate 1 g Manganese chloride tetrahydrate $1 \mathrm{~g}$, citrate $0.001 \mathrm{~g}$, water $1000 \mathrm{ml}$, added whit $1 \%$ filtered glucose, in static culture for 3 - 4 months at $28^{\circ} \mathrm{C}$.

The Coccidioides strain antigen was obtained from the filter at 8 weeks of development of the $C$ posadasii strain (Courtesy of Dr R Negroni, mycology Center College of Medicine, Argentina) in static culture in trypticase broth (trypticase $0.5 \%$, yeast extract $1 \%$, glucose $2 \%$ ) at $25^{\circ} \mathrm{C}-28^{\circ} \mathrm{C}$. The filtrate was obtained first in a sterilized paper filter and then in a bacteriological filter for a definitive sterilization. After controlling sterility for fungi and bacteria, merthiolate was added to the solution at 1:5000 for preservation, and the concentration was refrigerated at $2^{\circ} \mathrm{C}-8^{\circ} \mathrm{C}$.

The respective antigens for the skin reaction were performed in a similar manner, but the culture was agitated. The intradermal test and serological test were done in the intradermis with a metabolic antigen diluted $1 / 100$.

The serological test required a concentration of $100 \mathrm{mg} / \mathrm{ml}$ (control standardized for AGID, IMMY Immuno-Mycologics, Inc. Norman, EE. UU).

The respective antiserum was made in rabbits at the Infectious Disease Laboratory, Faculty of Veterinary Science, Universidad de Buenos Aires [12].

The tests were performed in triplicate and with both antigens; no cross-reactions were observed.

For the technique of intradermal inoculation, $0.1 \mathrm{ml}$ of each antigen was injected into the caudal fold of the cattle, in the neck in equines, in the vulvar lip of porcine and in the skin fold of dogs. Readings were taken after 48 and 72 hours, with observations of anerythematous papule with a $0.5 \mathrm{~cm}$ or wider mean diameter as a positive result for any reading.

\section{Results}

Sera from 30 pigs and 36 cattle were tested against the Coccidioides antigen, and two (2) were positive for the $\mathrm{M}$ band in the AGDI (Table 1).

The skin test was administered to 10 pigs and 10 cattle with three (3) pigs positive (Table 2).

The sera of 152 pigs, 182 cattle, and 30 dogs were tested with Histoplasma antigens, with six (6) cattle, twenty one (21) pigs and one (1) dog positive for the M band (Table 3).

In the skin test for Histoplasmosis, three (3) animals were positive: one dog, one cow and one horse (Table 4).

The samples for the Coccidioides test were from the Cordoba and Corrientes provinces.

The animals for the Histoplasma test were from the Buenos Aires, La Pampa, Santa Fe and Córdoba (southern zone) provinces and from the Corrientes/Chaco region.

Table 1. Coccidioidomycosis. Result of AGDI of the sera of domestic animals. 3.03\% of sera were positive.

\begin{tabular}{ccccc}
\hline Species & Geographic area & $N^{\circ}$ animals & Positive & Negative \\
Pigs & Córdoba & 30 & 1 & 29 \\
Cattle & Corrientes & 36 & 1 & 2 \\
Total & & 66 & 64 \\
\hline
\end{tabular}


Table 2. Coccidioidomycosis: Results of the skin test.

\begin{tabular}{ccccc}
\hline Species & Geographic area & N $^{\circ}$ animals & Positive & Negative \\
\hline Pigs & Córdoba & 10 & 3 & 0 \\
Cattle & Corrientes & 10 & 3 & 10 \\
Total & & 20 & 3 \\
\hline
\end{tabular}

Table 3. Histoplasmosis. Result of the AGDI in the sera of domestic animals. $7.71 \%$ of the sera were positive.

\begin{tabular}{|c|c|c|c|c|}
\hline Species & Geographic area & $\mathrm{N}^{\circ}$ animals & positive & negative \\
\hline Cattle & Buenos Aires & 100 & 1 & 99 \\
\hline Pigs & Sta. Fe/Cordoba & 83 & 9 & 74 \\
\hline Pigs & La Pampa & 68 & 12 & 56 \\
\hline Dogs & Buenos Aires & 30 & 1 & 29 \\
\hline Cattle & Chaco/Corrientes & 82 & 5 & 77 \\
\hline Total & & 363 & 28 & 335 \\
\hline
\end{tabular}

Table 4. Histoplasmosis: Results of the skin test.

\begin{tabular}{|c|c|c|c|c|}
\hline Species & Geographic area & $\mathrm{N}^{\circ}$ animals & Positive & Negative \\
\hline Cattle & Buenos Aires & 10 & 1 & 9 \\
\hline Pigs & Sta. Fe & 13 & 0 & 13 \\
\hline Dogs & Buenos Aires & 10 & 1 & 9 \\
\hline Horses & Buenos Aires & 10 & 1 & 9 \\
\hline Horses & Entre Rios & 10 & 0 & 10 \\
\hline Total & & 53 & 3 & 50 \\
\hline
\end{tabular}

\section{Discussion}

Contrary to the process used in humans, skin tests are not a common diagnostic test in animals. The skin test utilized most often in the detection of positive animals and for a control is the tuberculin test; the sensitivity presenting in different areas of the bovine skin has been extensively studied for this reason. The most sensitive areas are the neck and the crease in the groin. The anus caudal fold is less sensitive but offers twice the advantages compared with the other side, because it is relatively easy to access, especially while collecting from animals that are being managed for other procedures.

In pigs, the medial edge of the ears is used, but it is difficult for intradermal injections to overcome the skin thickness. In horses, dogs and cats, dermal tuberculin reactions are not used. The techniques involved the following areas of the animals: the caudal fold in cattle, the neck in horses, the vulvar lips in pigs and the inguinal crease in dogs, but were only performed in a small number of animals because the detection of at least one positive showed that the technique is feasible for use in individual diagnoses in cattle, horses, pigs, and dogs.

The immunodiffusion technique with these antigens detects less than $1 \mathrm{mg}$ of the M-specific antibody. Serum samples were taken from ecogeographical areas with potential to accommodate Histoplasma or Coccidioides, and animals were confirmed as being born in the area to minimize bias by cross-reactions [13]. In addition, the individuals selected were adults, thereby maximizing the time they had lived in the local area.

Immunodiffusion proved to be a simple, inexpensive and effective technique, feasible for use in detecting the precipitating antibodies, which are indicators of present or past infection. Furthermore, its ease of application as an epidemiological serological technique will make it useful for future studies of prevalence, determination of ecogeographic boundaries, and the detection of clinical cases. 
The AGDI technique was chosen because of its low cost, ease of use and high specificity. The detection of both the " $\mathrm{M}$ " and " $\mathrm{H}$ " bands is highly suggestive of active Histoplasmosis, regardless of other immunological tests. Previous authors have also used AGDI reactions in epidemiological surveys, and in comparison with other techniques, such as complement fixation, latex agglutination and ELISA, the AGDI lacks sensitivity, although it can reach $100 \%$ specificity [14]. In a study by Higgins et al. [14] in the USA, they concluded that serum antibodies against $C$. immitis could rarely be detected in healthy horses residing in areas in which the disease is endemic, and any horse with a detectable serum antibody titer should be evaluated after an interval of at least 3 weeks.

Histoplasma antibodies were detected in 1.78\% of the dog serum samples (four dogs of 224) in Brazil [2].

Using western blots, Canteros et al. [15] investigated the presence of P. brasiliensis, H. capsulatum and Coccidioides $s p$. in a rural area of Argentina called the Interfluvio Teuco-Bermejito, located in the Chaco province, to determine the presence of specific antibodies in sera from 89 domestic dogs inhabiting the area. Specific antibodies against $H$. capsulatum were found in 9/89 (10\%) of the serum samples.

\section{Conclusions}

The skin test with specific antigens for Coccidioidomycosis and Histoplasmosis can be used for studies and for individual diagnostics in cattle, equines, canines and for epidemiological surveys in cattle and pigs, according to the operation of the techniques in different species.

The serology, using IDGA for Histoplasmosis and Coccidioidomycosis, proved to be simple, inexpensive and effective, and feasible for use as an individual diagnostic tool in animals with present or past infection and in serological epidemiology with its ease of application.

The use of these methods can to be utilized for future studies in determining prevalence and for determining boundaries of endemic areas.

This is the first study to use different domestic animals to assess the presence of endemic fungal pathogens in Argentina. The results suggest that Histoplasma capsulatum and Coccidioides posadasii dimorphic fungal pathogens can infect animals in the regions studied.

\section{Competing Interests}

In this work there are no conflicts of interest.

\section{References}

[1] Greene, R.T. (2002) Coccidioidomycosis. In: Greene, C.E., Ed., Infectious Diseases of Dogs and Cats, 2nd Edition, WB Saunders Co., Philadelphia, 391-398.

[2] Cordeiro, R.A., Coelho, C.G., Brilhante, R.S., Sidrim, J.J., Castelo-Branco, D.S., Moura, F.B., et al. (2011) Serological Evidence of Histoplasma capsulatum Infection among Dogs with Leishmaniasis in Brazil. Acta Tropica, 119, $203-205$. http://dx.doi.org/10.1016/j.actatropica.2011.05.007

[3] Brown, J., Benedict, K., Park, B.J. and Thompson, G.R. (2013) Coccidioidomycosis: Epidemiology. Clinical Epidemiology, 5, 185-197. http://dx.doi.org/10.2147/CLEP.S34434

[4] Fisher, M.C., Koenig, G.L., White, T.I. and Taylor, J.W. (2002) Molecular and Phenotypic Description of Coccidioides posadasii sp. nov Previously Recognized as the Non-California Population of Coccidioides immitis. Mycologia, 94, 73-84. http://dx.doi.org/10.2307/3761847

[5] Kauffman, C.A. (2007) Histoplasmosis: A Clinical and Laboratory Update. Clinical Microbiology Reviews, 20, 115132. http://dx.doi.org/10.1128/CMR.00027-06

[6] Negroni, R. (2011) Histoplasmosis in Latin America. Biomédica, 31, 304. http://dx.doi.org/10.7705/biomedica.v31i3.597

[7] Mangiaterra, M., Alonso, J., Galvan, M., Giusano, G. and Gorodner, J. (1996) Histoplasmin and Paracoccidioidin Skin Reactivity in Infantile Population of Northern Argentina. Revista do Instituto de Medicina Tropical de São Paulo, 38, 349-353. http://dx.doi.org/10.1590/S0036-46651996000500005

[8] Pontón, J. (2002) Microbiological Diagnosis of the Mycoses. Revista Iberoamericana de Micología, 19, $25-29$.

[9] Torres-Rodríguez, J.M., Ribas-Forcadell, E., Gascón, J., López-Jodra, O. and Espasa, M. (2013) Diagnostic Usefulness of the Test Intradérmica with Histoplasmina, in Brazil. Mycopathologia, 175, 25-32. 
[10] Deepe, G.J. (2010) Histoplasma Capsulatum. In: Mandell, G.L., Bennett, J.E. and Dolin, R., Eds., Principles and Practice of Infectious Disease, 7th Edition. Churchill Livingstone Elsevier, Philadelphia, 3305-3313. http://dx.doi.org/10.1016/b978-0-443-06839-3.00264-2

[11] Graupmann-Kuzma, A., Valentine, B.A., Shubitz, L.F., Dial, S.M., Watrous, B. and Tornquist, S.J. (2008) Coccidioidomycosis in Dogs and Cats: A Review. Journal of the American Animal Hospital Association, 44, 226-235. http://dx.doi.org/10.5326/0440226

[12] Guida, N. (2010) Systemic mycoses. In: Gomez, N. and Guida, N., Eds., Infectious Diseases of Canine and Feline, Intermedica, Argentina, 250-270.

[13] Hung, C.Y., Ampel, N.M., Christian, L., Seshan, K.R. and Cole, G.T. (2000) A Major Cell Surface Antigen of Coccidioides immitis Which Elicits Both Humoral and Cellular Immune Responses. Infection and Immunity, 68, 584-593. http://dx.doi.org/10.1128/IAI.68.2.584-593.2000

[14] Higgins, J.C., Leith, G.S., Voss, E.D. and Pappagianis, D. (2005) Seroprevalence of Antibodies against Coccidioides immitis in Healthy Horses. Journal of the American Veterinary Medical Association, 226, 1888-1892. http://dx.doi.org/10.2460/javma.2005.226.1888

[15] Canteros, C.E., Madariaga, M.J., Lee, W., Rivas, M.C., Davel, G. and Iachini, R. (2010) Agentes de micosis endémicas en un area rural de Argentina: Estudio seroepidemiologico en perros. Revista Iberoamericana de Micología, 27, 14-19. http://dx.doi.org/10.1016/j.riam.2009.11.002

\section{Warmly welcome your paper submission to OALib Journal!}

- Publication on a daily basis

- 9 subject areas of science, technology and medicine

- Fair and rigorous peer-review system

- Fast publication process

- Article promotion in various social networking sites (LinkedIn, Facebook, Twitter, etc.)

- Widely-targeted and multidisciplinary audience to read your research

Submit Your Paper Online: Click Here to Submit

Contact Us: service@oalib.com 